\title{
A Singlet Oxygen Photogeneration and Luminescence Study of Unsymmetrically Substituted Mesoporphyrinic Compounds
}

\author{
Anabela Sousa Oliveira, ${ }^{1}$ Dumitru Licsandru, ${ }^{2}$ Rica Boscencu, ${ }^{3}$ Radu Socoteanu, ${ }^{4}$ \\ Veronica Nacea, ${ }^{3}$ and Luis Filipe Vieira Ferreira ${ }^{1}$ \\ ${ }^{1}$ Centro de Química-Física Molecular (CQFM) and Instituto de Nanociencias e Nanotecnologias (IN), Instituto Superior Técnico, \\ Universidade Técnica de Lisboa, Avenida Rovisco Pais, 1049-001 Lisbon, Portugal \\ ${ }^{2}$ Department of Physical Chemistry, Faculty of Chemistry, University of Bucharest, 4-12 Regina Elisabeta Bulevardul, \\ 030018 Bucharest, Romania \\ ${ }^{3}$ Department of Inorganic Chemistry, Faculty of Pharmacy, "Carol Davila" University of Medicine and Pharmacy, Bucharest, \\ 6 Traian Vuia Street, Sector 1, Bucharest, Romania \\ ${ }^{4}$ Institute of Physical Chemistry "I.G. Murgulescu" of the Romanian Academy, 202 Spl. Independentei, 060021 Bucharest-12, Romania
}

Correspondence should be addressed to Anabela Sousa Oliveira, asoliveira@ist.utl.pt

Received 6 June 2008; Revised 26 September 2008; Accepted 9 March 2009

Recommended by Mohamed Sabry Abdel-Mottaleb

This paper deals with a series of new unsymmetrically substituted mesoporphyrins: 5-(2-hydroxyphenyl)-10,15,20-trisphenyl-21,23-H-porphyrin $\left(\mathrm{TPPOH}_{\mathrm{O}}\right)$, 5-(3-hydroxyphenyl)-10,15,20-tris-phenyl-21,23-H-porphyrin $\left(\mathrm{TPPOH}_{\mathrm{M}}\right)$, 5-(4-hydroxyphenyl)-10,15,20-tris-phenyl-21,23-H-porphyrin $\left(\mathrm{TPPOH}_{\mathrm{P}}\right)$, 5-(2-hydroxyphenyl)-10,15,20-tris-butyl-21,23-H-porphyrin $\left(\mathrm{TBPOH}_{\mathrm{O}}\right)$, and their parent nonsubstituted compounds, respectively, 5,10,15,20-tetrakis-phenyl-21,23-H-porphyrin (TPP) and 5,10,15,20-tetrakis-butyl-21,23-H-porphyrin (TBP). Several photophysical studies were carried out to access the influence of the unsymmetrical substitution at the porphyrinic macrocycle on porthyrin's photophysical properties, especially porthyrin's efficiency as singlet oxygen sensitizers. The quantum yields of singlet oxygen generation were determined in benzene $\left(\Phi_{\Delta}(\mathrm{TPP})\right.$ $=0.66 \pm 0.05 ; \Phi_{\Delta}\left(\mathrm{TPPOH}_{\mathrm{O}}\right)=0.69 \pm 0.04 ; \Phi_{\Delta}\left(\mathrm{TPPOH}_{\mathrm{M}}\right)=0.62 \pm 0.04 ; \Phi_{\Delta}\left(\mathrm{TPPOH}_{\mathrm{P}}\right)=0.73 \pm 0.03 ; \Phi_{\Delta}(\mathrm{TBP})=0.76 \pm 0.03 ;$ $\left.\Phi_{\Delta}\left(\mathrm{TBPOH}_{\mathrm{O}}\right)=0.73 \pm 0.02\right)$ using the 5,10,15,20-tetraphenyl-21,23-H-porphine $\left(\Phi_{\Delta}(\mathrm{TPP})=0.66\right)$ and Phenazine $\left(\Phi_{\Delta}(\mathrm{Phz})=\right.$ $0.83)$ as reference compounds. Their fluorescence quantum yields were found to be $\left(\Phi_{\mathrm{f}}\left(\mathrm{TPPOH}_{\mathrm{O}}\right)=0.10 \pm 0.04 ; \Phi_{\mathrm{f}}(\mathrm{TPPOH})\right.$ $=0.09 \pm 0.03 ; \Phi_{\mathrm{f}}\left(\mathrm{TPPOH}_{\mathrm{P}}\right)=0.13 \pm 0.02 ; \Phi_{\mathrm{f}}(\mathrm{TBP})=0.08 \pm 0.03$ and $\Phi_{\mathrm{f}}\left(\mathrm{TBPOH}_{\mathrm{O}}\right)=0.08 \pm 0.02$ using 5,10,15,20-tetraphenyl21,23 -H-porphine as reference $\left.\Phi_{\mathrm{f}}(\mathrm{TPP})=0.13\right)$. Singlet state lifetimes were also determined in the same solvent. All the porphyrins presented very similar fluorescence lifetimes (mean values of $\tau_{\mathrm{S}}$ (with $\mathrm{O}_{2}$, air equilibrated) $=9.6 \pm 0.3$ nanoseconds and (without $\mathrm{O}_{2}$, argon purged) $=10.1 \pm 0.6$ nanoseconds, resp.). The phosphorescence emission was found to be negligible for this series of unsymmetrically substituted mesoporphyrins, but an E-type, thermally activated, delayed fluorescence process was proved to occur at room temperature.

Copyright (c) 2009 Anabela Sousa Oliveira et al. This is an open access article distributed under the Creative Commons Attribution License, which permits unrestricted use, distribution, and reproduction in any medium, provided the original work is properly cited.

\section{Introduction}

The role that porphyrins like hemoglobin or chlorophyll play in important processes as respiration or photosynthesis is well known and is now well understood $[1,2]$. In spite of the importance of porphyrins in the treatment of psoriasis, atheromatous plaque, and several viral and bacterial infections including AIDS [3-6], nowadays their use for cancer photodynamic therapy (PDT) has become undoubtly porphyrin's most relevant application [7-15]. Although some promising studies with other classes of compounds were already reported in literature [16-19], until now, very few PDT drugs were approved for human use and all of them are still porphyrins $[20,21]$.

The usefulness of porphyrins in cancer therapy originates from their ability for the generation of singlet oxygen [2225 , a very reactive species considered to be the cytotoxic agent in the photodegradation of malignant cells [7-25]. 
Once administrated to the patient, the photosensitizing PDT drugs are preferentially concentrated in malignant cells. After photosensitizer's selective concentration in cancer tissue, the tissue is irradiated with light suitable for the excitation of the sensitizer. If oxygen is nearby $\left({ }^{3} \mathrm{O}_{2}\right)$, an energy transfer process takes place, the sensitizer returns to its ground state, and an excited singlet state oxygen molecule $\left({ }^{1} \mathrm{O}_{2}{ }^{*}\right)$ is generated. Singlet oxygen is a very aggressive species that quickly reacts and destroys cancer cells which are closely located [7-25].

In addition to the need for the photosensitizers to have a strong absorption in the phototherapeutic window (the region of the visible spectrum located from $630 \mathrm{~nm}$ to $1000 \mathrm{~nm}$, where damage to human tissues is not important) $[26,27]$, high singlet oxygen quantum yield $[28,29]$, photostability $[27,30]$, no dark toxicity [31], also a good balance are needed between hydrophobic and hydrophilic properties of the photosensitizers that could help them to better locate at cellular level [32]. So, it should be possible to direct the photosensitizers to different cell components by "controlling" the peripheral groups at the porphyrinic macrocycle, while keeping unchanged, or even improving their photochemical properties. [32-35].

In the present work the photophysical properties and the singlet oxygen quantum yields of the unsymmetrically substituted mesoporphyrins presented in Scheme 1 were investigated. In the same scheme we further present the structure of their parent symmetrical tetrasubstituted porphyrins. This series of new unsymmetrically substituted mesoporphyrins allows a different charge distribution over the periphery of the tetrapyrollic macrocycle and consequently creates the possibility of controlling the transport of the photosensitizer molecule and its location at the cellular level without significant change of spectroscopic and photosensitizing properties [33]. The new structures suggest an unsymmetrical charge distribution over the macrocycle periphery of the tetrapyrollic ring, so that the porphyrinic molecule gets a slight amphoteric character that favors the transport of the photosensitizer to the cellular targets, both in polar (the external environment of the cell) and nonpolar (the lipidic double layer of the cellular membrane) media $[32,33]$.

\section{Experimental Section}

2.1. Materials. Commercilly available chemicals were used received from Sigma-Aldrich. All solvents were Merck pro analysis and were used without further purification.

Synthesis of the Unsymmetrically Substituted Mesoporphyrins. The unsymmetrically substituted mesoporphyrins understudy were synthesized according the methods proposed by Adler et al. [36] and Little et al. [37] and recently adapted by the authors $[38,39]$. Metal containing porphyrins were also already synthesized by us $[40,41]$ using the same method. After synthesis they were separated by column chromatography (with $\mathrm{Al}_{2} \mathrm{O}_{3}$ and silica gel as stationary phases and chloroform or benzene as eluent) and then characterized by ${ }^{1} \mathrm{H}$ and ${ }^{14} \mathrm{C}$ NMR, UV-Visible and IR spectrometry [38-41].

Sample Preparation. Solutions in benzene of the compounds with optical densities at $\lambda=377 \mathrm{~nm}\left(\mathrm{OD}^{337 \mathrm{~nm}}\right)$ varying from 0.30 up to 0.75 were used to study the different emission processes.

\subsection{Methods.}

Ground State Absorption. UV-Vis ground state absorption spectra were recorded using an Cary-OLIS 14 spectrophotometer. Further details are given elsewhere [42].

Time-Resolved Laser-Induced Luminescence (LIL) System. A schematic diagram of the LIL system is presented in $[42,43]$. Laser-induced luminescence experiments were carried out with an $\mathrm{N}_{2}$ laser (PTI model 2000 , ca. 600 ps pulses, $1.6 \mathrm{~mJ}$ per pulse). The light arising from the irradiation of the sample by the laser pulse is collected by a collimating beam probe coupled to an optical fiber (fused silica) and is detected by a gated intensified charge coupled device (Andor ICCD detector, based on the Hamamatsu S5769-0907). The ICCD was coupled to a fixed imaging compact spectrograph (Oriel, model FICS 77441). The system could be used either by capturing all light emitted by the sample or in a time-resolved mode by using a delay box (Stanford Research Systems, model D6535). The ICCD has high speed (2.2 nanoseconds) gating electronics and intensifier and works in the 200$900 \mathrm{~nm}$ wavelength range.

Time-resolved emission spectra were available in the nanosecond to second time, so in order to evaluate the luminescence behavior of the compounds, time-resolved luminescence experiments were carried out for time delays from 0 to 20 nanoseconds ( $\Delta t=5$ nanoseconds) and for time delays from 50 to $250 \mu \mathrm{s}(\Delta t=50 \mu \mathrm{s})$, respectively, in the presence and in the absence of oxygen, at $77 \mathrm{~K}$ and $298 \mathrm{~K}$. The photophysical properties measured in the presence of oxygen were evaluated from air equilibrated samples, and those measured in the absence of oxygen were evaluated from argon purged samples. Emission spectra may evidence some background which varies with the number of accumulations and the gain of the intensifier used to collect each timeresolved spectrum therefore, the $Y$-axis of each emission spectrum is labeled as luminescence intensity, arbitrary units.

System for Measuring Singlet Oxygen Luminescence. A schematic diagram of the experimental set up used for measuring singlet oxygen is presented in Figure 1. Singlet oxygen experiments were performed at room temperature with a PTI-PL2300 nitrogen laser $(337.1 \mathrm{~nm}$, ca. $600 \mathrm{ps}$ pulses, $\sim 1.6 \mathrm{~mJ} /$ pulse) with air equilibrated samples [19]. The emission from singlet oxygen at $\lambda=1270 \mathrm{~nm}$ was detected at 90 degrees to the incident laser beam-after passing through a $1270 \mathrm{~nm}$ interference filter (Corion) or a combination of long-wave pass filters $(1000 \mathrm{~nm}, 1100 \mathrm{~nm}$, $1200 \mathrm{~nm}$, CVI Laser Corp.) to reduce as much as possible the scattered radiation from the laser (shortly after the laser 

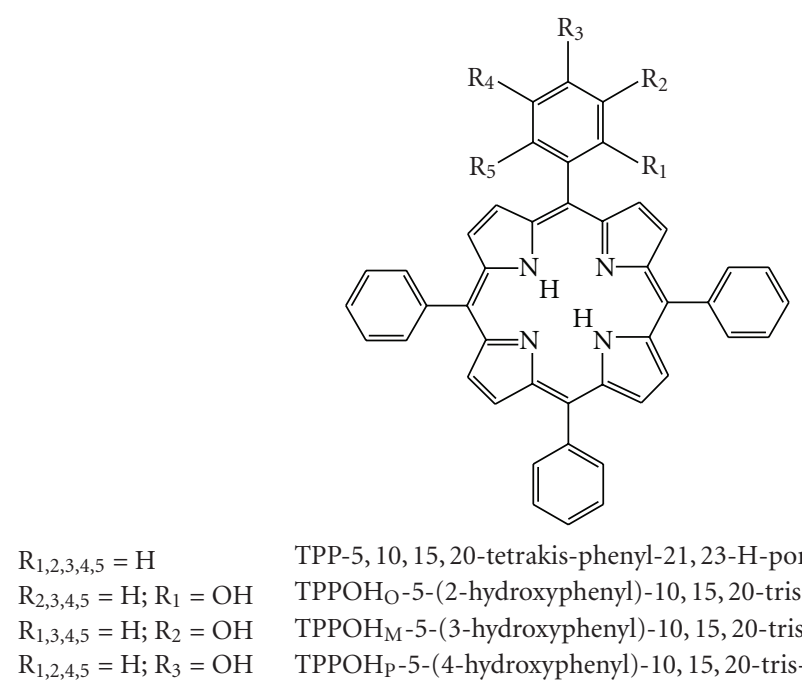
$\mathrm{TPPOH}_{\mathrm{M}}$-5-(3-hydroxyphenyl)-10, 15, 20-tris-phenyl-21, 23-H-porphyrin $\mathrm{TPPOH}_{\mathrm{P}}$-5-(4-hydroxyphenyl)-10, 15, 20-tris-phenyl-21, 23-H-porphyrin

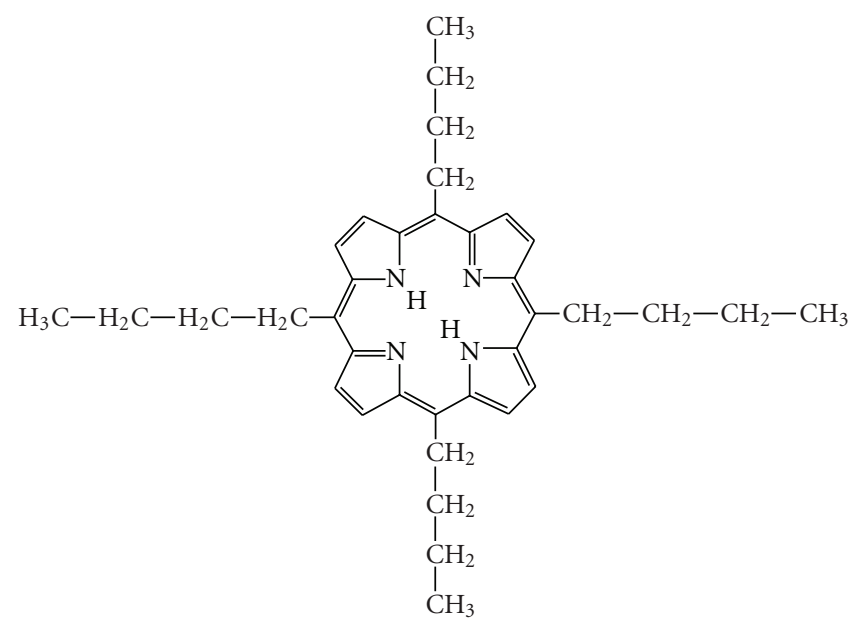

TBP-5, 10, 15, 20-tetrakis-butyl-21, 23-H-porphyrin

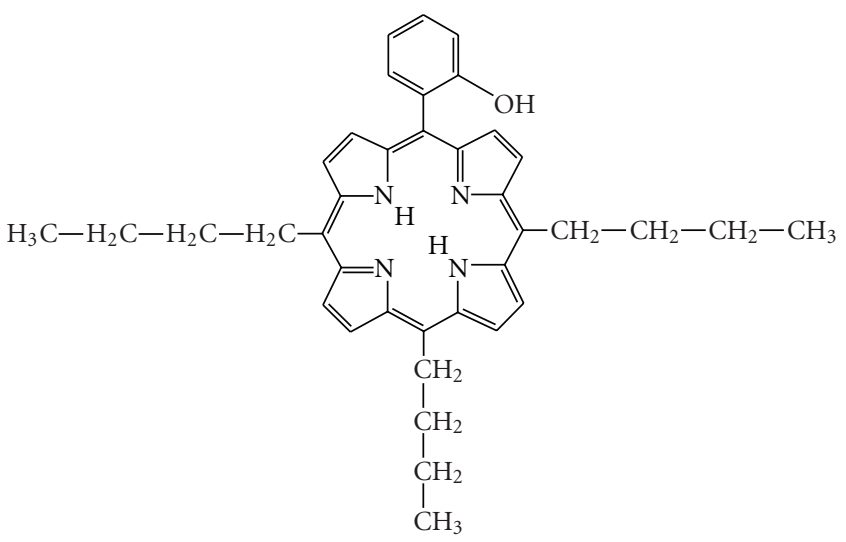

TBPOH $_{\mathrm{O}}$-5-(2-hydroxyphenyl)-10, 15, 20-tris-butyl-21, 23-H-porphyrin

SCHeme 1: Porphynin structures.

pulse)—by a $5 \mathrm{MHz}$ germanium photodiode (Judson, J16$8 S P-R 05 M-H S)$ working at room temperature. The signal was amplified with a preamplifier (Oriel 70732, $350 \mathrm{MHz}$ and Thorn EMI Electron Tubes A1 and/or A2). Decay curves were obtained with the help of an 8-bit AD-converter/recorder system (Fast TR50; $50 \mathrm{MHz}$ ), and each curve was the average of 60 decays. Samples and reference compounds solutions in benzene with optical density at $337 \mathrm{~nm}$ of 0.30 were excited 


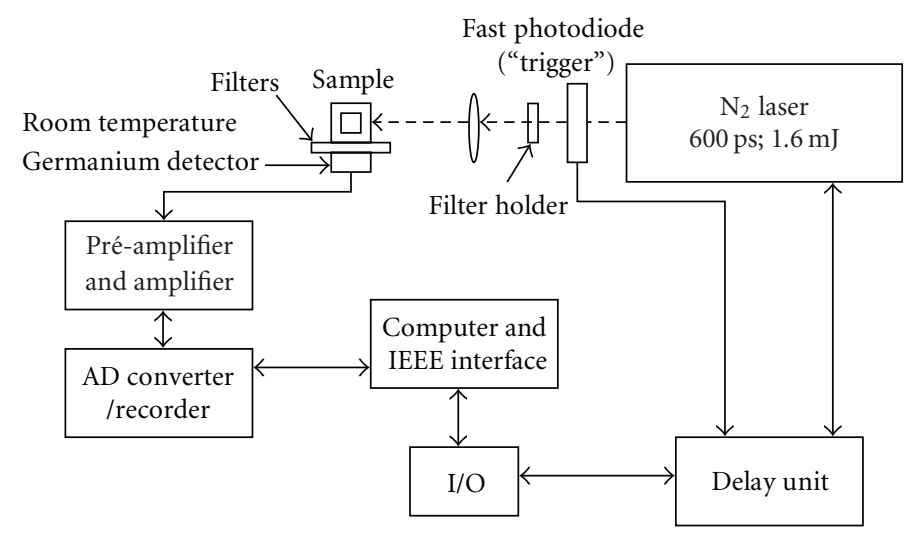

FigURE 1: Experimental setup for the measurement of singlet oxygen emission at $\lambda=1270 \mathrm{~nm}$.

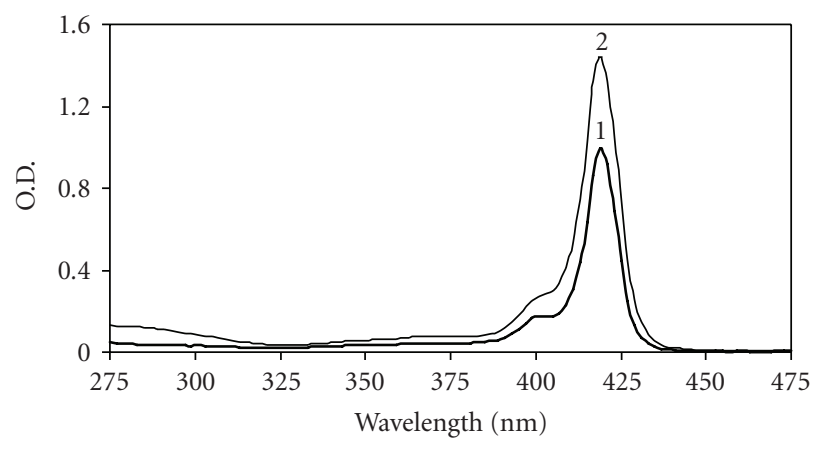

(a)

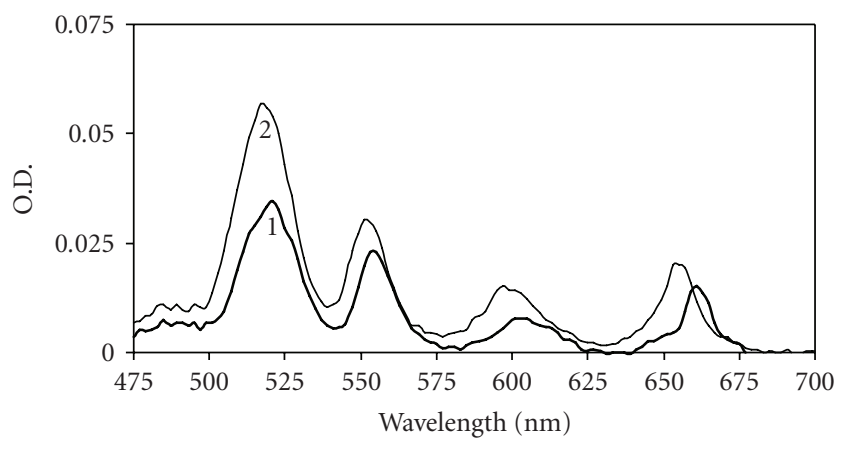

(b)

FIgURE 2: Absorption spectra of TBP (curve 1) and $\mathrm{TBPOH}_{\mathrm{O}}$ (curve 2) in benzene (room temperature, $4.5 \times 10^{-6} \mathrm{M}$ ). (a) Soret band and (b) $Q$ bands. Air equilibrated samples.

by $337.1 \mathrm{~nm} \mathrm{~N}_{2}$ laser pulses. The resultant emission curves were fitted with a single-exponential function to obtain the initial luminescence intensity at time $t=0$ (or the intensity at any other time $t$ ) after the laser pulse $[19,44,45]$. The laser energy was varied using a series of calibrated neutral density filters $(85.1 \%, 76.7 \%, 62.6 \%, 49.3 \%, 37.5 \%, 30.4 \%, 24.1 \%$, $18.4 \%$, and $12.8 \%)$.

\section{Results and Discussion}

3.1. Ground State Absorption. The UV-Vis absorption spectra of all porphyrins were measured in benzene, at room temperature. Figure 2 presents the absorption spectra for TBP and $\mathrm{TBPOH}_{\mathrm{O}}$, which are very similar to those of TPP and $\mathrm{TPPOH}_{\mathrm{x}}$ (x = ortho-, meta-, para-) [39], with their Soret band $(42 \mathrm{~nm})$ and four $Q$ bands $(514-516 \mathrm{~nm}, 548$ $550 \mathrm{~nm}, 590-592 \mathrm{~nm}$, and 648-652 nm), characteristic of $\mathrm{D}_{2 \mathrm{~h}}$ symmetry class. In the investigated range of concentrations $\left.10^{-6}-10^{-5} \mathrm{M}\right)$ no aggregate formation was observed.

The ground state absorption results are in full accordance with the evaluation of the electronic transitions made on the basis of the conformational structures obtained with HYPERCHEM [33], that already predicted that the substitutions made at TPP and TBP periphery's (phenyl at ortho-, meta-, para-positions) will not affect too much the spectral properties of the new compounds (and possibly also not affect their photosensitizing properties [2]).

\subsection{Fluorescence Emission and Fluorescence Quantum Yield.} In this study we intend to characterize the luminescent properties of the new unsymmetrically substituted mesoporphyrinic compounds in order to evaluate their importance as photosensitizers in photodynamic therapy. Figure 3 shows the corrected laser-induced fluorescence spectra for TPP, $\mathrm{TPPOH}_{\mathrm{x}}$ (x = ortho-, meta-, para-), TBP, and TBPOH $\mathrm{O}_{\mathrm{O}}$. For each porphyrin the fluorescence spectra were registered for different concentrations (more precisely for optical densities from 0.30 to 0.75 at the laser excitation wavelength, $337 \mathrm{~nm}$ ) and no significant changes on the spectral shape with concentration were detected (data not shown).

The shape of the spectra presented by the dyes is characteristic of the emission of the porphyrin free base [25]. All fluorescence spectra of the compounds investigated seem to keep this particular shape, with two bands located in the spectral region of $650-750 \mathrm{~nm}$ (see Table 1). Furthermore, the presence of the $-\mathrm{OH}$ group in only one of the ortho-, meta- or para-positions of phenyl ring leaves the fluorescence spectrum practically unchanged, when compared to that of the reference compound, TPP. This is not the case for the substitutions at meso-positions of porphyrinic 


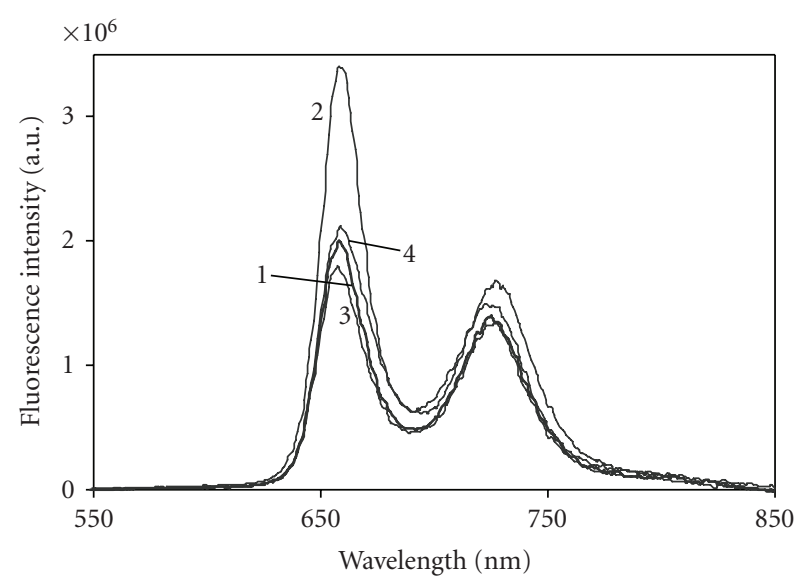

(a)

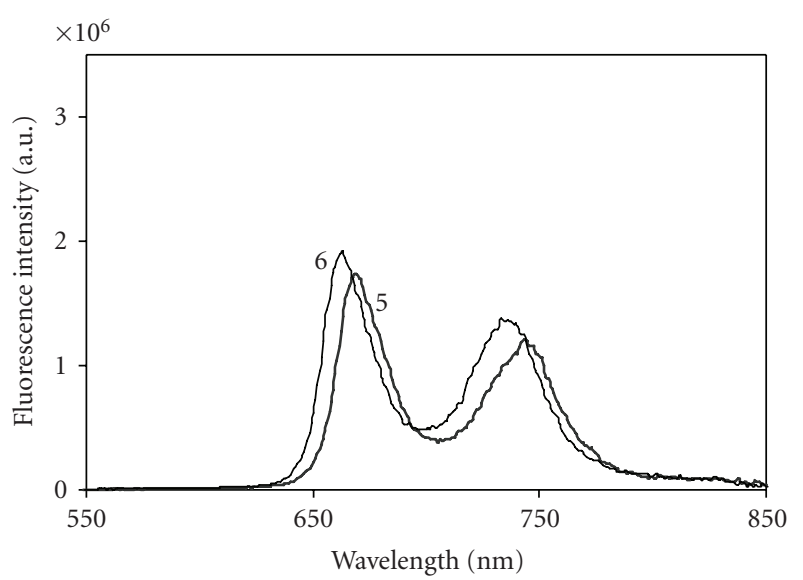

(b)

FIGURE 3: Laser-induced corrected fluorescence emission spectra of (a) TPP (curve 1), $\mathrm{TPPOH}_{\mathrm{O}}$ (curve 2), $\mathrm{TPPOH}_{\mathrm{M}}(\mathrm{curve}$ ), and TPPOH (curve 4) and of (b) TBP (curve 5) and $\mathrm{TBPOH}_{\mathrm{O}}$ (curve 6) in benzene, at room temperature. The optical density at the excitation wavelength was always 0.30 and the samples were air equilibrated.

TABLE 1: Wavelength maximum of the fluorescent emission bands, $\lambda$, and fluorescence quantum yield, $\Phi_{\mathrm{F}}$, for the series of unsymmetrically substituted mesoporphyrins in benzene for air equilibrated samples.

\begin{tabular}{lccc}
\hline Compound & \multicolumn{2}{c}{$\lambda(\mathrm{nm})$} & $\Phi_{\mathrm{F}}$ \\
\hline TPP & 661 & 726 & $0.13^{*}$ \\
TPPOH $_{\mathrm{O}}$ & 660 & 728 & $0.10 \pm 0.04$ \\
TPPOH $_{\mathrm{M}}$ & 660 & 728 & $0.09 \pm 0.03$ \\
TPPOH $_{\mathrm{P}}$ & 660 & 728 & $0.13 \pm 0.02$ \\
TBP $_{\text {TBPOH }_{\mathrm{O}}}^{670}$ & 745 & $0.08 \pm 0.03$ \\
\hline
\end{tabular}

*From [44].

macrocycle: from TPP to TBP, the differences between the positions of fluorescence emission bands are approximately 10 and $20 \mathrm{~nm}$, respectively, (661 and $726 \mathrm{~nm}$ for TPP; 670 and $745 \mathrm{~nm}$ for TBP). As can be seen from Figure 3 and Table 1, after changing a butyl group by a hydroxyphenyl group (going from TBP to $\mathrm{TBPOH}_{\mathrm{O}}$ ), the observed effect is the same, although with a smaller extension. In this case, the difference is still relevant (664 and $738 \mathrm{~nm}$ for $\mathrm{TBPOH}_{\mathrm{O}}$ ).

The fluorescence quantum yields, $\phi_{\mathrm{F}}$, were determined according the equation, $\phi_{\mathrm{F}}{ }^{\mathrm{x}}=\phi_{\mathrm{F}}{ }^{0}\left(\mathrm{~S}^{\mathrm{x}} / \mathrm{S}^{0}\right)[42,46]$, where $\mathrm{x}$ and 0 refer to the compound understudy and to the standard, respectively, and $S$ is the integrated area of the corrected emission spectra. The values of fluorescence quantum yields were determined relatively to TPP $\left(\phi_{\mathrm{F}}=0.13[47]\right)$ and are presented in Table 1.

From the analysis of these values, it can be seen that $\mathrm{TPP}$ and $\mathrm{TPPOH}_{\mathrm{P}}$ showed the highest fluorescence quantum yield, 0.13 , contrary to butyl-substituted compounds (TBP and $\mathrm{TBPOH}_{\mathrm{O}}$ ), which exhibited the smallest value in this series, 0.08 . The fact that the values of fluorescence quantum yield determined are generally low for all the investigated porphyrins shows that fluorescence is not the main radiative

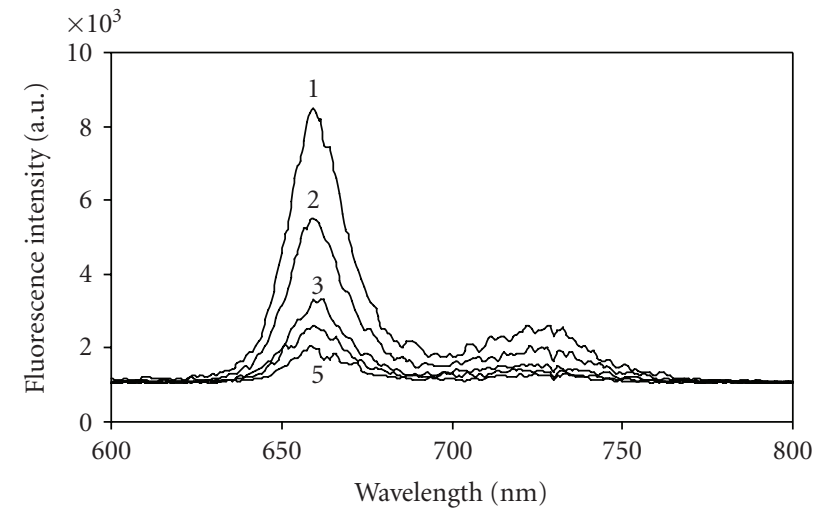

Figure 4: Time-resolved laser-induced fluorescence emission spectra of $\mathrm{TPPOH}_{\mathrm{O}}$ in benzene at room temperature registered 0 , 5, 10, 15, and 20 nanoseconds (resp., curves 1 to 5) after laser pulse, at $337 \mathrm{~nm}$. The spectrum was registered with a gate of 100 nanoseconds for air equilibrated samples.

deactivation pathway to the ground state. This indicates that triplet state population may be significant and if that is the case, the quantum yield for singlet oxygen generation is probably high as well. This fact allows us to anticipate promising photosensitizing properties for the new compounds.

Time-resolved laser-induced fluorescence emission experiments were carried out for all the porphyrins in benzene. The results were very similar for all the compounds investigated. Figure 4 shows a representative result for $\mathrm{TPPOH}_{\mathrm{O}}$; fluorescence curves registered $0,5,10,15$, and 20 nanoseconds after the laser excitation pulse, at $337 \mathrm{~nm}$.

From time-resolved fluorescence measurements it was possible to estimate singlet state fluorescence lifetimes, $\tau_{\mathrm{S}}$, which is also an important parameter to characterize the fluorescent properties of the new porphyrinic compounds [48]. 
TABLE 2: Fluorescence lifetime, $\tau_{\mathrm{S}}$, for the series of unsymmetrically substituted mesoporphyrin compounds in benzene and in the presence of oxygen (air equilibrated samples) and in the absence of oxygen (argon purged samples).

\begin{tabular}{|c|c|c|c|}
\hline \multirow[b]{2}{*}{ Compound } & \multicolumn{2}{|c|}{$\tau_{\mathrm{S}}(\mathrm{ns})$} & \multirow{2}{*}{$\begin{array}{c}k_{\mathrm{s}} \\
\left(\mathrm{mol}^{-1} \mathrm{~s}^{-1}\right) \times 10^{-9}\end{array}$} \\
\hline & $\begin{array}{c}\text { With } \mathrm{O}_{2} \\
\text { (air equilibrated) }\end{array}$ & $\begin{array}{l}\text { Without } \mathrm{O}_{2} \\
\text { (argon purged) }\end{array}$ & \\
\hline TPP & 9.7 & 10.8 & 10.9 \\
\hline $\mathrm{TPPOH}_{\mathrm{O}}$ & 9.4 & 9.8 & 5.4 \\
\hline $\mathrm{TPPOH}_{\mathrm{M}}$ & 9.5 & 10.5 & 10.2 \\
\hline $\mathrm{TPPOH}_{\mathrm{P}}$ & 9.8 & 10.6 & 7.3 \\
\hline TBP & 9.6 & 9.8 & 2.0 \\
\hline $\mathrm{TBPOH}_{\mathrm{O}}$ & 9.3 & 9.4 & 0.5 \\
\hline
\end{tabular}

Table 2 shows $\tau_{\mathrm{S}}$ for each compound understudy, in the presence and in the absence of oxygen.

The rate constant of singlet state quenching by molecular oxygen, $k_{S}$, was also determined according the equation [25]:

$$
k_{\mathrm{S}}=\frac{\left(\tau_{\mathrm{S}}\right)^{-1}-\left(\tau_{\mathrm{S}}^{0}\right)^{-1}}{\left[\mathrm{O}_{2}\right]}
$$

where $\tau_{\mathrm{S}}{ }^{0}$ and $\tau_{\mathrm{S}}$ are, respectively, the singlet state fluorescence lifetimes of the compound in solution in the absence and in the presence of oxygen.

All the air equilibrated solutions of the porphyrins understudy present very similar singlet state fluorescence lifetimes ranging from 9.3 to 9.8 nanoseconds (mean value of $\tau_{\mathrm{S}}$ (with $\mathrm{O}_{2}$, air equilibrated samples) $=9.6 \pm 0.3$ nanoseconds), which only slightly increase in the absence of oxygen, for the argon purged samples, from 9.4 to 10.8, (mean value of $\tau_{\mathrm{S}}$ (without $\mathrm{O}_{2}$, argon purged samples) $=$ $10.1 \pm 0.6$ nanoseconds), implying a small rate constant of singlet state quenching by molecular oxygen, as actually was found (see Table 2). This value of mean singlet state fluorescence lifetime is very close to the value reported for TPP in toluene [25]. Ortho derivatives seem to present slightly shorter lifetimes relative to their parent porphyrins, as can also be observed from Table 2 .

3.3. Delayed Fluorescence. Time-resolved laser-induced emission experiments on longer time scales, carried out for air equilibrated samples both at room temperature and $77 \mathrm{~K}$, showed that the phosphorescent emission of this series of compounds is negligible (result not shown). This is in agreement with the values reported in the literature for this class of compounds $\left(\Phi_{\mathrm{P}} \approx 10^{-5}\right)[25,47]$.

However with these experiments another process was also evidenced: for all the compounds understudy, $1 \mu \mathrm{s}$ after the laser pulse, and in the absence of the molecular oxygen (argon purged samples), it was still possible to measure spectra similar to those of the fluorescence emission, as can be observed at Figures 5(b) and 5(e) to be compared with Figures 5(a) and 5(d) and also Figures 3 and 4. Figure 5 presents results for TPP and TBP in benzene, but very similar results were observed for all the other porphyrins understudy.
TABLE 3: Delayed fluorescence lifetime, $\tau_{\mathrm{DF}}$, for the series of unsymmetrically substituted mesoporphyrins in benzene (at room temperature, in the absence of oxygen) (argon purged samples).

\begin{tabular}{lcc}
\hline Compound & $\begin{array}{c}\tau_{\mathrm{DF}}(\mu \mathrm{s}) \\
\mathrm{T}=293 \mathrm{~K} \\
\text { Without } \mathrm{O}_{2} \\
\text { (argon purged) }\end{array}$ & $\begin{array}{c}\tau_{\mathrm{DF}}(\mu \mathrm{s})^{*} \\
\mathrm{~T}=77 \mathrm{~K}\end{array}$ \\
$\begin{array}{l}\text { Without } \mathrm{O}_{2} \\
\text { (argon purged) }\end{array}$ \\
\hline $\mathrm{TPP}$ & 12.0 & 74 \\
$\mathrm{TPPOH}_{\mathrm{O}}$ & 9.3 & - \\
$\mathrm{TPPOH}_{\mathrm{M}}$ & 9.1 & - \\
$\mathrm{TPPOH}_{\mathrm{P}}$ & 11.4 & - \\
$\mathrm{TBP}_{\mathrm{TBPOH}}$ & 12.8 & - \\
\hline
\end{tabular}

* The intensities of the emission bands at $\mathrm{T}=77 \mathrm{~K}$ for the compounds presented in the table were very small, so that TPP was the only one for which the intensity was sufficiently high to allow an acceptable precision for the delayed fluorescence lifetime determination.

At such long time delay all of the directly excited fluorescence was extinguished [48]. The intensities of these new emission bands are smaller (ten times in amplitude) than the ones belonging to true fluorescence spectra (compare intensities from Figures 5(a) and 5(b) for TPP or from Figures 5(d) and 5(e) for TBP). The fact, that these spectra are located at the same wavelengths as those of fluorescent emission (from 650 to $750 \mathrm{~nm}$ ), and in a different wavelength region from that of the typical phosphorescence (800 to $950 \mathrm{~nm}$ ) from porphyrins, pointed out to the existence of a delayed fluorescence process [25, 47] (see Figure 5(b)). In the presence of the molecular oxygen (air equilibrated samples) these long-lived emissions were not observed (see Figures $5(\mathrm{a})$ and $5(\mathrm{~d}))$.

When the measurement of these long emissions was carried out at lower temperatures $(\mathrm{T}=77 \mathrm{~K})$, the intensity of the emission process was visibly reduced, becoming almost undetectable for $\mathrm{TPPOH}_{\mathrm{O}}, \mathrm{TPPOH}_{\mathrm{M}}$, TBP (see Figure 5(f)), and $\mathrm{TBPOH}_{\mathrm{O}}$. This result, presented at Figures 5(c) and 5(f), respectively, for TPP and TBP, shows that this is a thermally activated or E-type delayed fluorescence process [48]. The higher values of the temperature allowed the population of the higher-energy levels, so that the electronic transfer from the first excited triplet, $\mathrm{T}_{1}$, to the first excited singlet, $\mathrm{S}_{1}$, (reverse ISC) was favored. Consequently, the $\mathrm{T}_{1}$ quenching controls the quenching rate of $S_{1}$, to the ground state, $\mathrm{S}_{0}$, (fluorescence). The process of delayed fluorescence quenching by molecular oxygen is always predominant, being limited only by the solubility of molecular oxygen in a particular solvent [48]. The values of the delayed fluorescence lifetime, $\tau_{\mathrm{DF}}$, are presented in Table 3.

Although the values observed do not vary too much within the series, TBP and $\mathrm{TBPOH}_{\mathrm{O}}$ display slightly longer delayed fluorescence lifetimes and so higher values of singlet oxygen generation quantum yields could be expected. The reason for that is evident: a higher $\tau_{\mathrm{DF}}$ means that the molecule stays longer in the first excited triplet, $T_{1}$, and consequently there is a higher probability of the energy to transfer to the ground state of the oxygen molecule. As we will see in the next section this was observed in fact. 


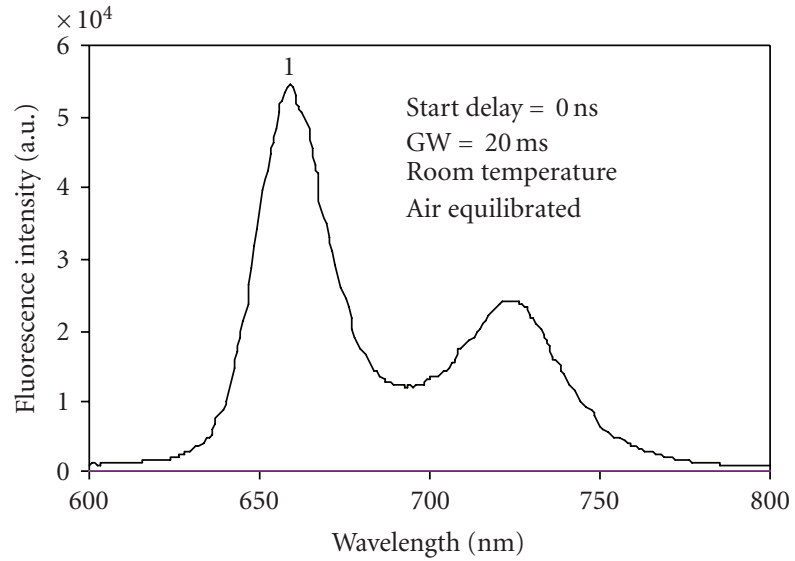

(a)

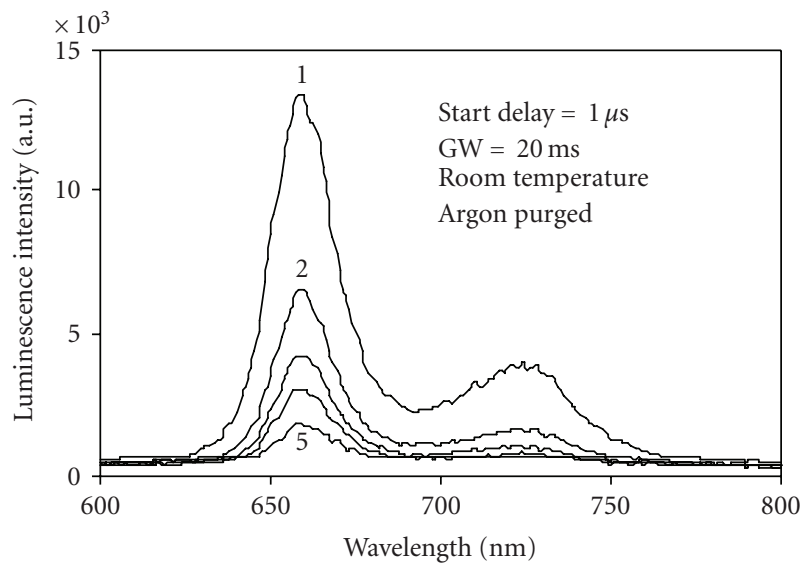

(b)

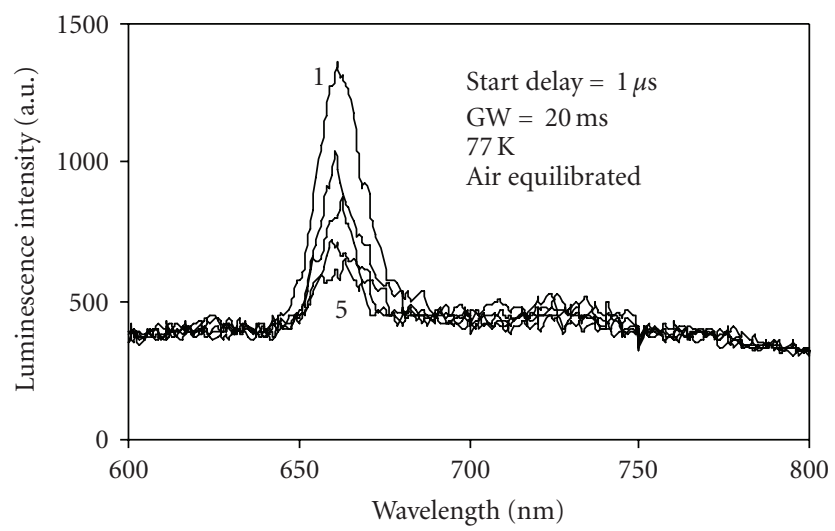

(c)

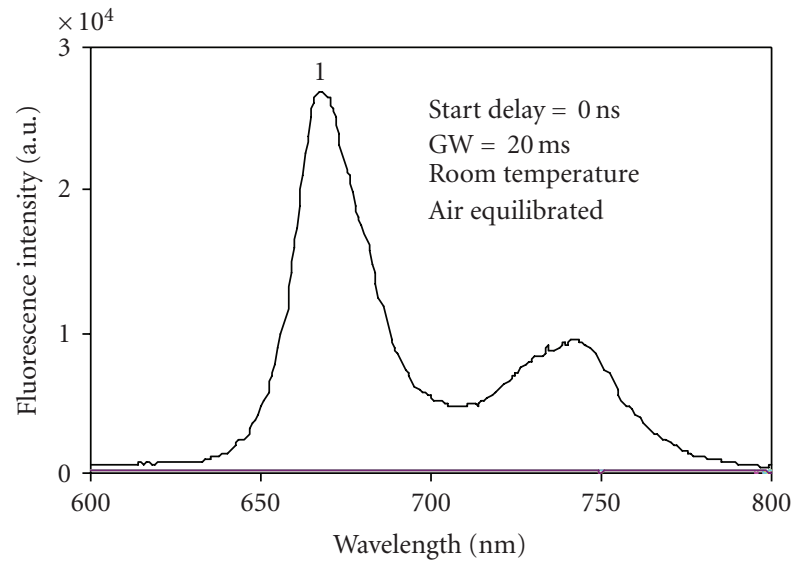

(d)

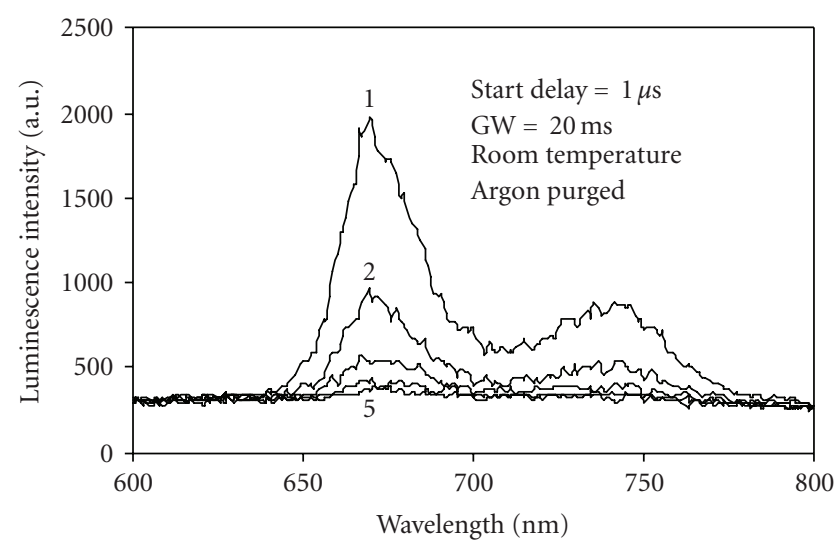

(e)

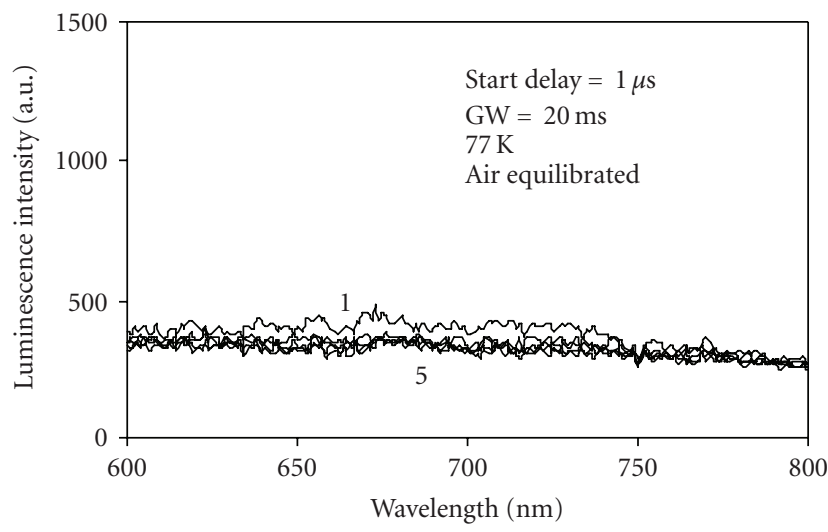

(f)

FIGURE 5: Time-resolved laser-induced luminescence emission spectra of TPP (left column) and TBP (right column) in benzene. Spectra were registered with a $20 \mathrm{~ms}$ gate with at (a), (d) room temperature, in presence of $\mathrm{O}_{2}$ (air equilibrated samples), (b), (e) room temperature, in absence of $\mathrm{O}_{2}$ (argon purged samples), (c), (f) $\mathrm{T}=77 \mathrm{~K}$, in presence of $\mathrm{O}_{2}$ (air equilibrated samples), (50, 100, 150, 200 and $250 \mu \mathrm{s}$, after laser pulse, resp., for curves 1 to 5 at $337 \mathrm{~nm}$ ). The start delay was zero in (a) and (d) and $1 \mu \mathrm{s} \mathrm{in} \mathrm{(b),} \mathrm{(c),} \mathrm{(e),} \mathrm{and} \mathrm{(f).}$

3.4. Efficiency of Singlet Oxygen Photogeneration. As it was said before the photosensitized generation of the singlet oxygen was the main motivation for the synthesis of these new compounds, mainly because the role that these species play in photodynamic therapy of cancer (PDT).
Phenazine in benzene $\left(\phi_{\Delta} \mathrm{Phz}=0.83\right)$ and $5,10,15,20$ tetraphenyl-21,23-H-porphine in benzene $\left(\phi_{\Delta \mathrm{TPP}}=0.66\right)$ [44] with an optical density of 0.30 [45] at the excitation wavelength $(337 \mathrm{~nm})$ were used as references. For references and samples with matching optical densities 


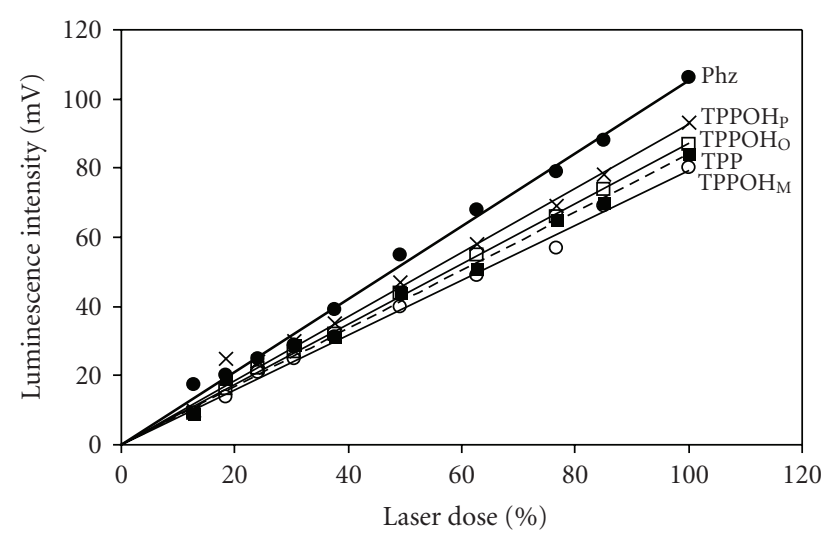

(a)

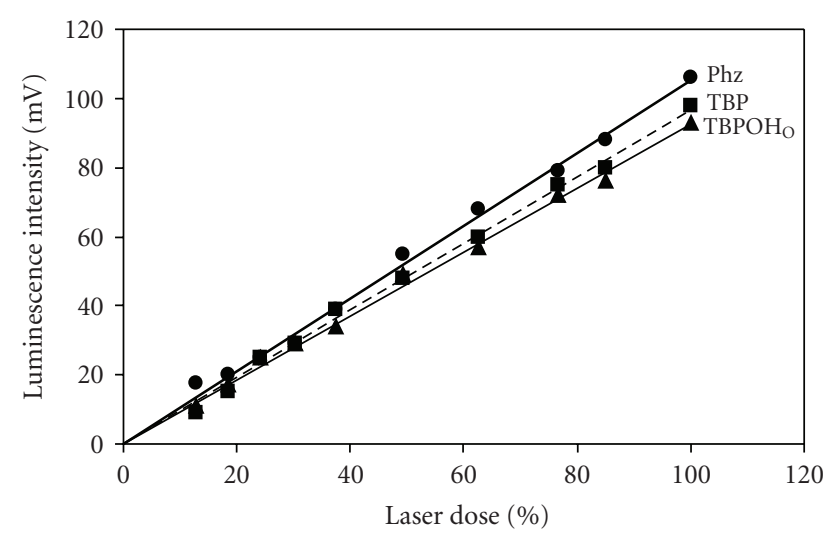

(b)

Figure 6: Plots of initial singlet oxygen $\left({ }^{1} \mathrm{O}_{2}\right)$ luminescence intensity versus laser dose percentage for optically matched samples (O.D. = 0.30) of (a) Phenazine, (TPP (_ _ $), \mathrm{TPPOH}_{\mathrm{O}}, \mathrm{TPPOH}_{\mathrm{M}}$, and $\mathrm{TPPOH}_{\mathrm{P}}$ and (b) Phenazine (__ ), TBP (_- ${ }_{--}$and $\mathrm{TBPOH}_{\mathrm{O}}$. Air equilibrated samples in benzene at room temperature; excitation wavelength was $337 \mathrm{~nm}$.

$\left(\mathrm{OD}^{337 \mathrm{~nm}}=0.30\right)$ accurate calibration curves with linear dependence of singlet oxygen emission intensity versus laser energy were obtained by placing neutral density filters in the excitation laser path length. A comparison of the slopes for the samples understudy and for the reference yielded $\phi_{\Delta}$ in a straightforward manner, that is, $\phi_{\Delta}{ }^{\mathrm{x}}=\phi_{\Delta}{ }^{0}$ $\left(\right.$ slope $_{\mathrm{x}} /$ slope $_{0}$ ), where $\mathrm{x}$ and 0 refer, respectively, to the compound understudy and to the standard, as presented in Figure 6. Alternatively, $\phi_{\Delta}{ }^{\mathrm{x}}=\phi_{\Delta}{ }^{0}\left(\mathrm{I}_{\mathrm{x}} / \mathrm{I}_{0}\right)$, where $\mathrm{I}$ is the intensity of luminescence at time $t$, can also be used $[19,44,45]$. On this range of concentrations there was no dependence on concentration of the quantum yield of singlet oxygen production. The values of the singlet oxygen quantum yields, $\Phi_{\Delta}$, obtained in this study are shown in Table 4.

From the analysis of the singlet oxygen quantum yields a first observation can be made: similar or even higher values of singlet oxygen quantum yields were found for all the new compounds in comparison to those of the reference, TPP. Thus attempts to control the charge density at the macrocycle
TABLE 4: Singlet oxygen quantum yields, $\Phi_{\Delta}$, and photodynamic efficiency, $\alpha$, for the series of unsymmetrically substituted mesoporphyrins in benzene for air equilibrated samples, at room temperature.

\begin{tabular}{lcccc}
\hline \multirow{2}{*}{ CompoundSlope } & \multirow{2}{*}{$\Phi_{\Delta}$} & \multicolumn{2}{c}{$\alpha$ (mole/second) at $\lambda_{\mathrm{axc}}$} \\
& & & $633 \mathrm{~nm}$ & $650 \mathrm{~nm}$ \\
\hline $\mathrm{TPP}^{*}$ & 0.84 & $0.66 \pm 0.05$ & 9.99 & 43.07 \\
$\mathrm{TPPOH}_{\mathrm{O}}$ & 0.87 & $0.69 \pm 0.04$ & 9.38 & 53.73 \\
$\mathrm{TPPOH}_{\mathrm{M}}$ & 0.79 & $0.62 \pm 0.04$ & 8.32 & 31.78 \\
$\mathrm{TPPOH}_{\mathrm{P}}$ & 0.93 & $0.73 \pm 0.03$ & 10.58 & 40.51 \\
$\mathrm{TBP}$ & 0.96 & $0.76 \pm 0.03$ & 10.49 & 20.04 \\
$\mathrm{TBPOH}_{\mathrm{O}}$ & 0.93 & $0.73 \pm 0.02$ & 5.19 & 18.31 \\
$\mathrm{Phz}^{*}$ & 1.05 & 0.83 & - & - \\
\hline
\end{tabular}

$*$ Used as reference compounds $\left(\phi_{\Delta \mathrm{Phz} / \text { Benzene }}=0.83 ; \phi_{\Delta \mathrm{TPP} / \text { Benzene }}=0.66\right.$ [44].)

periphery did not affect visibly the photosensitizing properties of the compounds, and sometimes these properties were even improved.

From the analysis of the delayed fluorescence lifetimes, $\tau_{\mathrm{DF}}$, it can be observed that singlet oxygen quantum yields are higher for the compounds having high values of $\tau_{\mathrm{DF}}$. Moreover, the magnitude of the sequence $\tau_{\mathrm{DF}}$ is very similar to that of $\Phi_{\Delta}$. We concluded that therefore the more the population of the first triplet state, $T_{1}$, is significant, the higher the probability of the energy transfer from the photosensitizer porphyrin, to the oxygen, with the consequent production of singlet oxygen is.

3.5. Evaluation of the Photodynamic Efficiency. Table 4 presents also the calculated values of the photodynamic efficiency factor, $\alpha$. The intrinsic efficiency of the photodynamic process can be quantified by the photodynamic efficiency factor, $\alpha$, which is defined by the yield of singlet oxygen generation (mole/second) for the incident power unity density $\left(\mathrm{W} / \mathrm{cm}^{2}\right)$, at the specific irradiation wavelength on the concentration unit of the photosensitizer, according to $\boldsymbol{\alpha}=$ $1.925 * 10^{-5} * \lambda \Phi_{\Delta} \varepsilon_{s}$, where $\lambda$ is their radiation wavelength, in $\mathrm{nm}$, and $\varepsilon_{S}$ the photosensitizer molar absorption coefficient, in $\mathrm{M}^{-1} \mathrm{~cm}^{-1}[49,50]$.

We can observe the difference between the estimations of the photosensitization activity on the basis of singlet oxygen quantum yields, $\Phi_{\Delta}$, and those on photodynamic efficiencies, $\alpha$ : at the wavelengths where the human tissues are irradiated within ordinary PDT protocols ( 620 to $670 \mathrm{~nm}$ ), compounds showing higher $\Phi_{\Delta}$, like TBP or $\mathrm{TBPOH}_{\mathrm{O}}$, presented lower values of $\alpha$. This is because, besides $\Phi_{\Delta}$ contribution, this parameter reflects also the contribution of the absorption coefficient of the photoensitizer at the irradiation wavelength. Furthermore, we have also to account for the value of the attenuation coefficient of the biological environment, at the specific wavelength of irradiation, $1 / \mu_{\text {eff. In fact in a PDT }}$ treatment the ideal irradiation wavelength is a compromise between photodynamic efficiency and attenuation coefficient of the environment. Actually, even for deeper tissues, the later supposes higher efficiencies in case of use of radiations in the 
red region of the spectra $\left(1 / \mu_{\text {eff }}\right.$ has values of $0.02,0.95,2.7$, 1.2 , resp., at $545,633,680$, and $800 \mathrm{~nm})$.

\section{Conclusions}

In this paper several unsymmetrically substituted mesoporphyrins $\left(\mathrm{TPPOH}_{\mathrm{x}}, \mathrm{x}=\right.$ ortho-, meta-, or para- and $\mathrm{TBPOH}_{\mathrm{O}}$ ) were synthesized by a method recently adapted by the authors with the objective of promoting the amphoteric character of their molecular structures and in this way to improve their capacity of being transported to different cellular targets without losing the good singlet oxygen sensitizing properties of their parent compounds, the nonsubstituted mesoporphyrins (TPP and TBP). Ground state absorption and fluorescence emission properties were not significantly affected by the unsymmetrical substitution. Fluorescence quantum yields and fluorescence lifetimes were of the same order of magnitude of those of TPP and TBP. Furthermore a delayed fluorescence process was observed for all the compounds investigated. Singlet oxygen quantum yield determination confirmed that the initial objectives of the work were largely achieved since the unsymmetrically substituted mesoporphyrins under evaluation presented singlet oxygen quantum yields of the same order of the magnitude or even larger than TPP. The evaluation of the photodynamic efficiency factor clearly illustrated that the high singlet oxygen quantum yield of a photosensitizer is not a full warranty of its adequacy for PDT use.

\section{Acknowledgments}

Equipment was financed by Project Praxis/P/Qui/10023/ 98 and Praxis/P/Qui/10023/2004. The first author gratefully acknowledges Fundação para a Ciência e Tecnologia for Grant SFRH/BPD/26798/2006 and Projects PTDC/QUI/65510/2006 and PTDC/Qui/70153/2006.

\section{References}

[1] K. M. Kadish, K. M. Smith, and R. Guilard, The Porphyrin Handbook, vol. 1 and 13, Academic Press, San Diego, Calif, USA, 2000.

[2] L. R. Milgrom, "Introduction: the colour purple," in The Colours of Life: An Introduction to the Chemistry of Porphyrins and Related Compounds, chapter 1, pp. 1-2, Oxford University Press, Oxford, UK, 1977.

[3] D. W. Dixon, L. G. Marzilli, and R. F. Schinazi, "Porphyrins as agents against the human immunodeficiency virus," Annals of the New York Academy of Sciences, vol. 616, pp. 511-513, 1990.

[4] A. R. Neurath, N. Strick, P. Haberfield, and S. Jiang, "Rapid prescreening for antiviral agents against HIV-1 based on their inhibitory activity in site-directed immunoassays. II. Porphyrins reacting with the V3 loop of gp120," Antiviral Chemistry and Chemotherapy, vol. 3, no. 1, pp. 55-63, 1992.

[5] D. L. DeCamp, L. M. Babé, R. Salto, et al., "Specific inhibition of HIV-1 protease by boronated porphyrins," Journal of Medicinal Chemistry, vol. 35, no. 18, pp. 3426-3428, 1992.
[6] A. K. Debnath, S. Jiang, N. Strick, K. Lin, P. Haberfield, and A. Robert Neurath, "Three-dimensional structure-activity analysis of a series of porphyrin derivatives with anti-HIV1 activity targeted to the V3 loop of the gp120 envelope glycoprotein of the human immunodeficiency virus type 1 ," Journal of Medicinal Chemistry, vol. 37, no. 8, pp. 1099-1108, 1994.

[7] J. Moan, "Porphyrin photosensitization and phototherapy," Photochemistry and Photobiology, vol. 43, no. 6, pp. 681-690, 1986.

[8] J. D. Spikes, "Photosensitizing properties of porphyrins in modell cell systems," in Porphyrins in Tumor Phototherapy, A. Andreoni and R. Cubeddu, Eds., pp. 51-60, Plenum, New York, NY, USA, 1984.

[9] J. D. Spikes and G. Jori, "Photodynamic therapy of tumours and other diseases using porphyrins," Lasers in Medical Science, vol. 2, no. 1, pp. 3-15, 1987.

[10] B. W. Henderson and T. J. Dougherty, "How does photodynamic therapy work?" Photochemistry and Photobiology, vol. 55, no. 1, pp. 145-157, 1992.

[11] T. J. Dougherty, C. J. Gomer, B. W. Henderson, et al., "Photodynamic therapy," Journal of the National Cancer Institute, vol. 90, no. 12, pp. 889-905, 1998.

[12] R. Bonnett and M. C. Berenbaum, Porphyrin Photosensitization, Plenum, New York, NY, USA, 1983.

[13] R. Bonnett, Chemical Aspects of Photodynamic Therapy, Advanced Chemistry Texts, Gordon and Breach, Singapore, 2000.

[14] L. I. Grosseweiner, "Photodynamic therapy," in The Science of Phototherapy, chapter 8, pp. 139-155, CRC Press, London, UK, 1994.

[15] C. Schweitzer and R. Schmidt, "Physical mechanisms of generation and deactivation of singlet oxygen," Chemical Reviews, vol. 103, no. 5, pp. 1685-1757, 2003.

[16] M. Wainwright, "Non-porphyrin photosensitizers in biomedicine," Chemical Society Reviews, vol. 25, no. 5, pp. 351-359, 1996.

[17] R. W. Redmond, M. B. Srichai, J. M. Bilitz, D. D. Schlomer, and M. Krieg, "Merocyanine dyes: effect of structural modifications on photophysical properties and biological activity," Photochemistry and Photobiology, vol. 60, no. 4, pp. 348-355, 1994.

[18] M. Krieg, J. M. Bilitz, M. B. Srichai, and R. W. Redmond, "Effects of structural modifications on the photosensitizing properties of dialkylcarbocyanine dyes in homogeneous and heterogeneous solutions," Biochimica et Biophysica Acta, vol. 1199, no. 2, pp. 149-156, 1994.

[19] P. F. Santos, L. V. Reis, I. Duarte, et al., "Synthesis and photochemical evaluation of iodinated squarylium cyanine dyes," Helvetica Chimica Acta, vol. 88, no. 5, pp. 1135-1143, 2005.

[20] R. R. Allison, G. H. Downie, R. Cuenca, X.-H. Hu, C. J. H. Childs, and C. H. Sibata, "Photosensitizers in clinical PDT," Photodiagnosis and Photodynamic Therapy, vol. 1, no. 1, pp. 27-42, 2004.

[21] M. Kreimer-Birnbaum, "Modified porphyrins, chlorins, phthalocyanines, and purpurins: second-generation photosensitizers for photodynamic therapy," Seminars in Hematology, vol. 26, no. 2, pp. 157-173, 1989.

[22] F. Wilkinson, W. P. Helman, and A. B. Ross, "Quantum yields for the photosensitized formation of the lowest electronically excited singlet state of molecular oxygen in solution," Journal of Physical and Chemical Reference Data, vol. 22, no. 1, pp. 113-262, 1993. 
[23] A. K. Haylett, F. I. McNair, D. McGarvey, et al., "Singlet oxygen and superoxide characteristics of a series of novel asymmetric photosensitizers," Cancer Letters, vol. 112, no. 2, pp. 233-238, 1997.

[24] S. Kimel, B. J. Tromberg, W. G. Roberts, and M. W. Berns, "Singlet oxygen generation of porphyrins, chlorins, and phthalocyanines," Photochemistry and Photobiology, vol. 50, no. 2, pp. 175-183, 1989.

[25] E. Zenkevich, E. Sagun, V. Knyukshto, et al., "Photophysical and photochemical properties of potential porphyrin and chlorin photosensitizers for PDT," Journal of Photochemistry and Photobiology B, vol. 33, no. 2, pp. 171-180, 1996.

[26] S. Stolik, J. A. Delgado, A. Pérez, and L. Anasagasti, "Measurement of the penetration depths of red and near infrared light in human "ex vivo" tissues," Journal of Photochemistry and Photobiology B, vol. 57, no. 2-3, pp. 90-93, 2000.

[27] R. W. Boyle and D. Dolphin, "Structure and biodistribution relationships of photodynamic sensitizers," Photochemistry and Photobiology, vol. 64, no. 3, pp. 469-485, 1996.

[28] F. Postigo, M. Mora, M. A. DeMadariaga, S. Nonell, and M. L. Sagristá, "Incorporation of hydrophobic porphyrins into liposomes: characterization and structural requirements," International Journal of Pharmaceutics, vol. 278, no. 2, pp. 239254, 2004.

[29] I. Scalise and E. N. Durantini, "Photodynamic effect of metallo 5-(4-carboxyphenyl)-10,15,20-tris (4-methylphenyl) porphyrins in biomimetic AOT reverse micelles containing urease," Journal of Photochemistry and Photobiology A, vol. 162, no. 1, pp. 105-113, 2004.

[30] I. J. MacDonald and T. J. Dougherty, "Basic principles of photodynamic therapy," Journal of Porphyrins and Phthalocyanines, vol. 5, no. 2, pp. 105-129, 2001.

[31] E. S. Nyman and P. H. Hynninen, "Research advances in the use of tetrapyrrolic photosensitizers for photodynamic therapy," Journal of Photochemistry and Photobiology B, vol. 73, no. 1-2, pp. 1-28, 2004.

[32] F. Ricchelli, G. Jori, S. Gobbo, and M. Tronchin, "Liposomes as models to study the distribution of porphyrins in cell membranes," Biochimica et Biophysica Acta, vol. 1065, no. 1, pp. 42-48, 1991.

[33] D. Licsandru, Characterization by spectral methods of some unsymmetrically-substituted mesoporphyrins with a potential biological activity, Ph.D. thesis, Bucarest University, Bucharest, Romania, 2001.

[34] R. Boscencu, D. Licsandru, C. Gârd, and V. Nacea, "Testari fitobiologice ale unor noi compusi meso-porfirinici nesimetric substituiti," Farmacia, vol. LIII, no. 2, pp. 105-110, 2005.

[35] R. Boşcencu, D. Licsandru, V. Nacea, and D. Negoiu, "The conformational modelling of some new porphyrinic compounds and their complexes with $\mathrm{Zn}$ (II) and $\mathrm{Cu}(\mathrm{II})$. The anticipation of electronical transitions that occur in the UVVis absorption spectra," Revista de Chimie, vol. 55, no. 7, pp. 503-507, 2004.

[36] A. D. Adler, F. R. Longo, J. D. Finarelli, J. Goldmacher, J. Assour, and L. Korsakoff, "A simplified synthesis for mesotetraphenylporphine," The Journal of Organic Chemistry, vol. 32, no. 2, p. 476, 1967.

[37] R. A. Little, J. A. Anton, P. A. Loach, and J. A. Ibers, "The synthesis of some substituted tetraarylporphyrins," Journal of Heterocyclic Chemistry, vol. 12, pp. 343-349, 1974.

[38] R. Boşcencu, D. Licsandru, and V. Nacea, "Unsymmetricallysubstituted porphyrine derivative and the method for its synthesis," Patent Application no. 00367, submitted to the Romanian State Office for Inventions and Trademarks, April 2005.

[39] R. Boşcencu, D. Licsandru, R. Socoteanu, A. S. Oliveira, and L. F. Vieira Ferreira, "Synthesis and spectral characterisation of some unsymetrically substituted mesoporphyrinic compounds," Revista de Chimie, vol. 58, pp. 498-501, 2007.

[40] R. Boşcencu, R. Socoteanu, A. S. Oliveira, and L. F. Vieira Ferreira, "Studies on $\mathrm{Zn}(\mathrm{II})$ monohydroxyphenyl mesoporphyrinic complexes. Synthesis and characterization," Journal of the Serbian Chemical Society, vol. 73, no. 7, pp. 713-726, 2008.

[41] R. Boşcencu, R. Socoteanu, A. S. Oliveira, L. F. Vieira Ferreira, V. Nacea, and G. Patrinoiu, "Synthesis and characterization of some unsymmetrically-substituted mesoporphyrinic monohydroxyphenyl complexes of copper(II)," Polish Journal of Chemistry, vol. 82, no. 3, pp. 509-521, 2008.

[42] A. M. Botelho do Rego and L. F. Vieira Ferreira, "Photonic and electronic spectroscopies for the characterization of organic surfaces and organic molecules adsorbed on surfaces," in Handbook of Surfaces and Interfaces of Materials, H. S. Nalwa, Ed., vol. 2, chapter 7, pp. 275-313, Academic Press, Boston, Mass, USA, 2001.

[43] L. F. Vieira Ferreira, A. S. Oliveira, and J. C. Netto-Ferreira, "Room temperature phosphorescence of aromatic ketones included into hydrophobic powdered substrates," in Fluorescence Microscopy and Fluorescent Probes 3, A. Kotyc, Ed., vol. 3, pp. 199-208, Espero, Prague, Czech, 1999.

[44] J. C. Scaiano, R. W. Redmond, B. Mehta, and J. T. Arnason, "Efficiency of the photoprocesses leading to singlet oxygen $\left(1 \delta_{\mathrm{g}}\right)$ generation by $\alpha$-terthienyl: optical absorption, optoacoustic calorimetry and infrared luminescence studies," Photochemistry and Photobiology, vol. 52, no. 4, pp. 655-659, 1990.

[45] M. Mir, L. M. G. Jansen, F. Wilkinson, J. L. Bourdelande, and J. Marquet, "Efficiency of singlet oxygen generation from the triplet states of nitrophenyl ethers," Journal of Photochemistry and Photobiology A, vol. 113, no. 2, pp. 113-117, 1998.

[46] L. F. Vieira Ferreira and S. M. B. Costa, "Fluorescence quantum yield evaluation of strongly absorbing dye solutions as a function of the dye concentration," Journal of Luminescence, vol. 48-49, part 1, pp. 395-399, 1991.

[47] A. Harriman, "Luminescence of porphyrins and metalloporphyrins-part 1: zinc(II), nickel(II) and manganese(II) porphyrins," Journal of the Chemical Society, Faraday Transactions 1, vol. 76, pp. 1978-1985, 1980.

[48] A. Gilbert and J. Baggott, Essentials of Molecular Photochemistry, Blackwell Scientific, Oxford, UK, 1991.

[49] J. M. Steinke and A. P. Shepherd, "Diffusion model of the optical absorbance of whole blood," Journal of the Optical Society of America A, vol. 5, no. 6, pp. 813-822, 1988.

[50] E. M. Waterfield, M. E. Renke, C. B. Smits, et al., "Wavelengthdependent effects of benzoporphyrin derivative monoacid ring A in vivo and in vitro," Photochemistry and Photobiology, vol. 60, no. 4, pp. 383-387, 1994. 


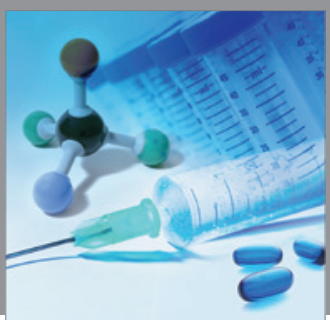

International Journal of

Medicinal Chemistry

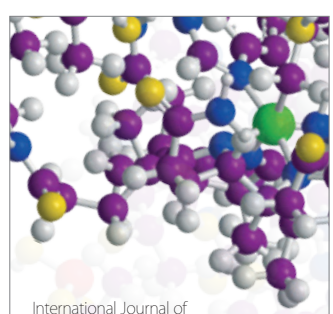

Carbohydrate Chemistry

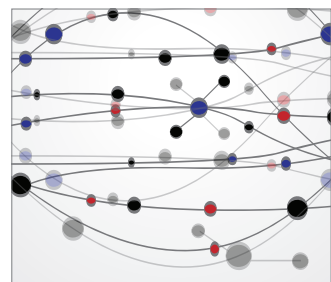

The Scientific World Journal
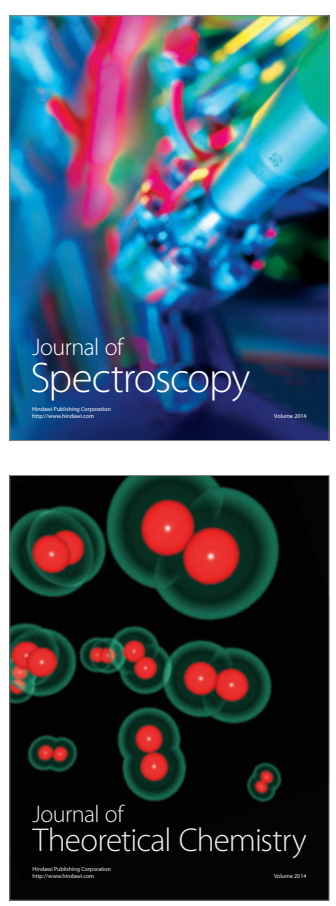
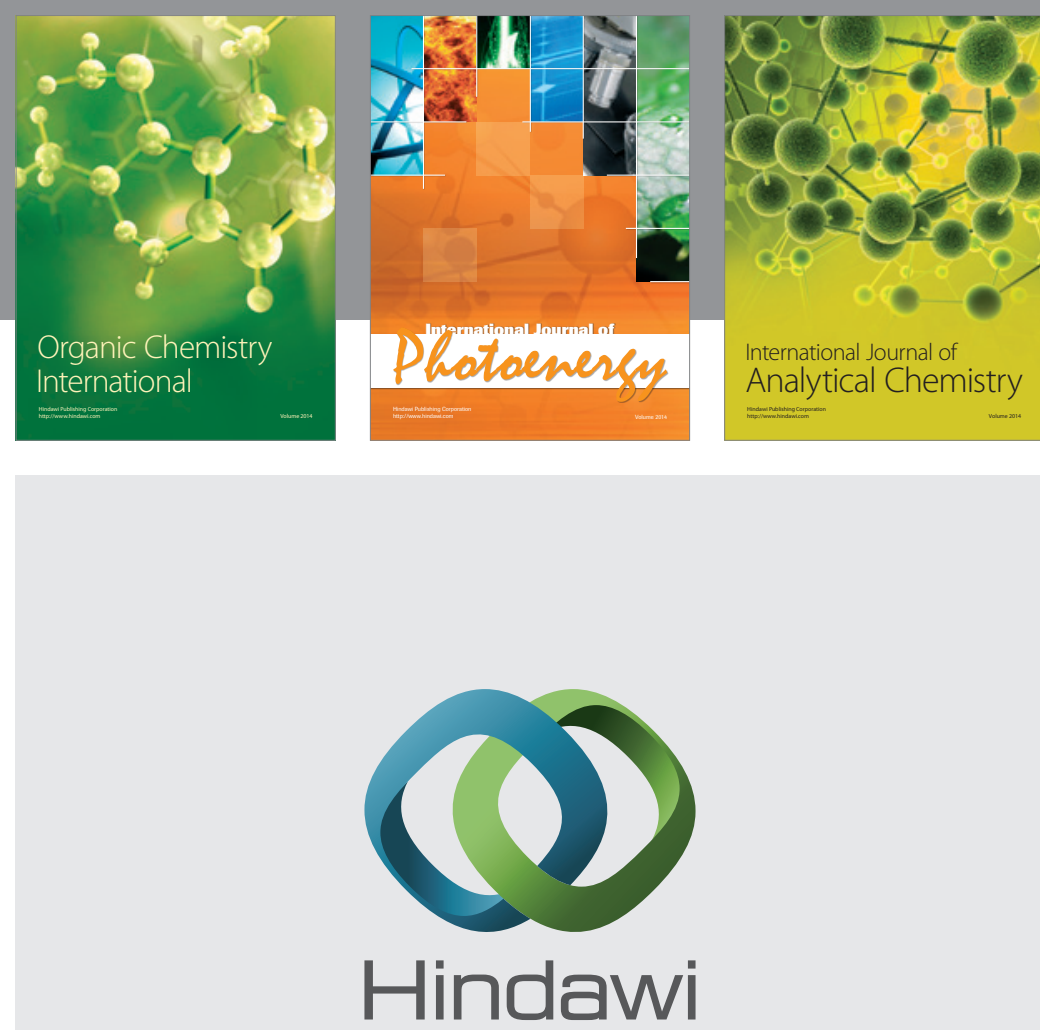

Submit your manuscripts at

http://www.hindawi.com
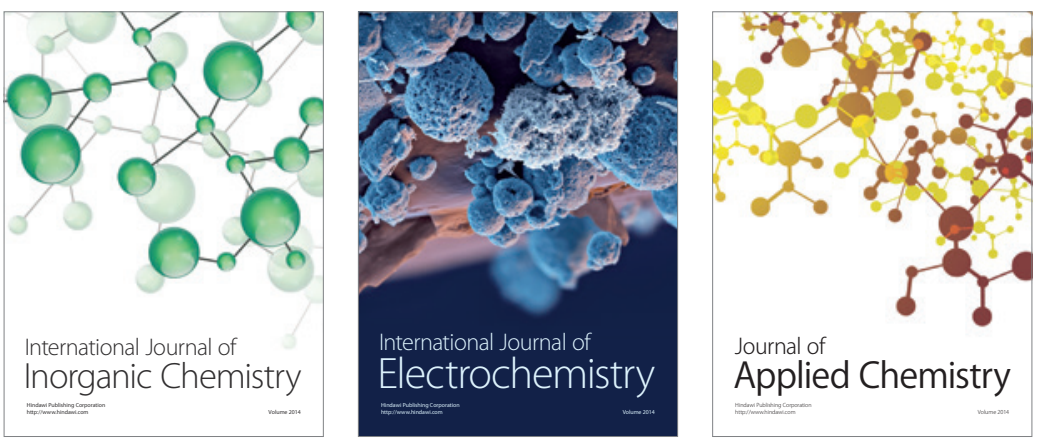

Journal of

Applied Chemistry
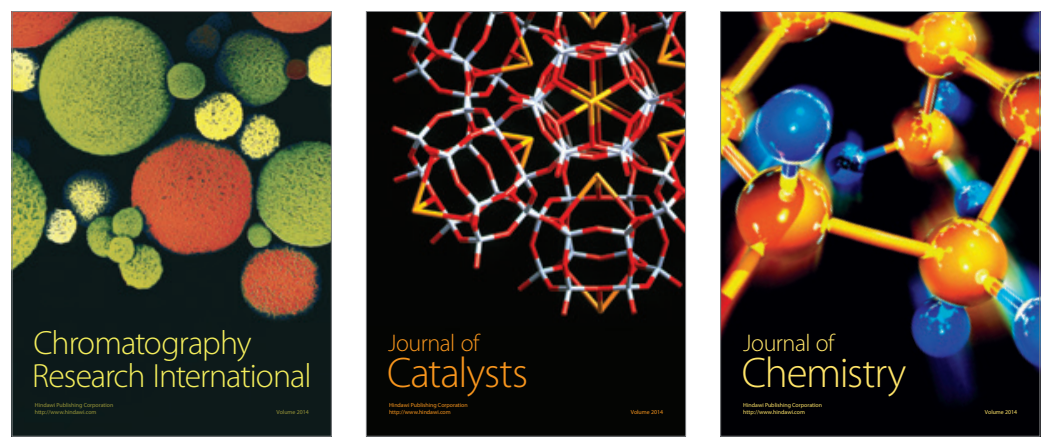
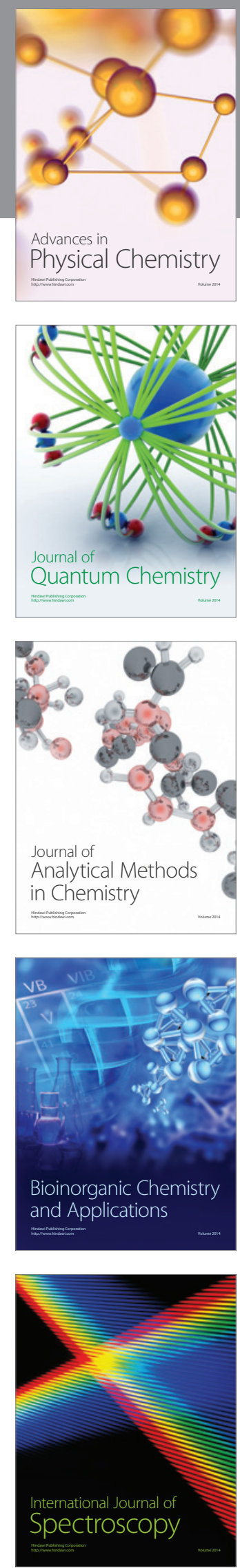